\title{
AVALIAÇÃO DE COTISTAS E NÃO COTISTAS: UMA ANÁLISE DO DESEMPENHO ACADÊMICO E DA EVASÃO EM UM CURSO DE GRADUAÇÃO EM ADMINISTRAÇÃO.
}

\author{
AMÁLIA BORGES DARIO \\ Universidade de Federal de Santa Catarina \\ amaliabdario@gmail.com \\ ROGÉRIO DA SILVA NUNES \\ Universidade Federal de Santa Catarina \\ rogerio.sn@ufsc.br
}

\section{RESUMO}

Diante da importância dos processos avaliativos em políticas públicas e da escassa investigação comparando cotistas e não cotistas em universidades públicas brasileiras, o trabalho buscou avaliar duas dimensões de tal contexto, evasão e desempenho acadêmico no curso de graduação em Administração de uma universidade federal. Para tal, a pesquisa utilizou-se de uma abordagem quantitativa, buscando no sistema de acompanhamento acadêmico da instituição todos os ingressantes no curso de Administração (diurno e noturno) entre 2008 e 2012, discriminando por forma de ingresso, situação acadêmica e Índice de Aproveitamento Acadêmico (IAA). Os dados foram coletados no primeiro semestre de 2017, obtendo uma população de 942 ingressantes no período. Os resultados mostram diferenças entre os grupos cotistas e não cotistas tanto com relação à evasão quanto ao desempenho acadêmico. O grupo dos dos cotistas exibe um IAA médio relativamente menor e um maior índice de abandono e desistência. Também mostra que existe diferença entre cotistas autodeclarados negros e egressos de escola pública, tendo estes evasão menor e desempenho acadêmico melhor.

Palavras-chave: Avaliação. Política de Cotas. Ações afirmativas. Desempenho acadêmico. Evasão. 


\section{INTRODUÇÃO}

No Brasil, durante as últimas décadas, houve um amplo crescimento do número de vagas no ensino superior. Em 2007, por exemplo, o número de matrículas na educação superior foi de 4.880.381, enquanto que em 1991 eram 1.565.056 - um crescimento acima de $311 \%$ (INEP, 2016). Essa expansão trouxe, além do maior número de matrículas nas instituições de ensino superior (IES), a necessidade do aprimoramento da gestão universitária tendo em vista a limitação dos recursos.

Este crescimento nominal foi oportunizado por diversas políticas de acesso: Exame Nacional do Ensino Médio; Sistema de Seleção Unificada; Programa Universidade para Todos; Fundo de Financiamento ao Estudante do Ensino Superior; Plano de Reestruturação e Expansão das Universidades Federais e Políticas de Ações Afirmativas. Além do acesso, algumas dessas ações visam também reduzir desigualdades sociais estabelecidas historicamente no Brasil; como é o caso das políticas afirmativas.

As políticas de ações afirmativas visam, em caráter provisório, incentivar grupos historicamente desfavorecidos e reparar a exclusão socioeconômica vivenciada por eles, assim apresentam natureza compensatória. De acordo com Souza e Brandalise (2016), essas ações devem proporcionar a diversificação de culturas e uma maior representatividade aos grupos minoritários, além de defender o multiculturalismo.

As cotas, política que reserva vagas para ingresso no ensino superior público, foram convertidas em política pública nacional em 2012 a partir da Lei $\mathrm{n}^{\mathrm{o}}$. 12.711. Entretanto, iniciativas começaram desde 2003 pela pioneira postura da Universidade do Estado do Rio de Janeiro. Em 2008 essa ação já era realidade em mais de 20 universidades federais (MIELKI et al., 2008).

Na Universidade Federal de Santa Catarina (UFSC), a política de cotas foi implantada a partir do vestibular de 2007, para ingressantes em 2008, mas sua discussão começou na instituição em 2001 (UFSC, 2007; MIELKI et al., 2008). No período 2008 a 2012, enquanto a política de cotas não era nacionalmente compulsória, a UFSC destinava $30 \%$ das vagas do vestibular, em cada curso, para candidatos que cursaram integralmente o ensino fundamental e médio em instituições públicas $(20 \%)$ e para candidatos autodeclarados negros que cursaram integralmente o ensino fundamental e médio em instituições públicas (10\%). Também foi implementado acesso diferenciado a candidatos pertencentes aos povos indígenas (UFSC, 2007).

Em um cenário de expansão do ensino superior em um ambiente mais exigente e competitivo, a gestão universitária - apesar do seu forte aspecto político (PASCUCI et al., 2016) - carece de dados institucionais para alicerçar suas decisões a fim de viabilizar o melhor uso de seus recursos. Dessa forma, a avaliação de suas políticas exerce papel essencial nesse processo, haja vista ser um instrumento para a melhoria da eficiência dos gastos, da qualidade da gestão e do controle social alcançado por meio de publicidade (RAMOS e SCHABBACH, 2012).

Para Costa e Castanhar (2003, p. 972), o propósito da avaliação é orientar os gestores na tomada de decisão, "orientando-os quanto à continuidade, necessidade de correções ou mesmo suspensão de uma determinada política ou programa". Nessa perspectiva, o INEP (2006) aponta que as pressões ocasionadas pelos sistemas de avaliação podem gerar mudanças comportamentais e de gestão nas IES. Além disso, o processo avaliativo proporciona à instituição autoconhecimento, oferecendo dados para repensar e redesenhar seus processos.

Não obstante, em que pesem diversos estudos desenvolvidos na área de avaliação da educação superior com relação ao desempenho acadêmico e evasão (p.ex. DAVOK, 
BERNARD, 2016; PEIXOTO et al., 2016; QUEIROZ et al., 2015; TRESOLDI et al., 2015), os gestores da educação superior demandam informações e diagnósticos relacionados às importantes transformações ocorridas nas últimas décadas para a tomada de decisão. Apesar da dificuldade em generalizar os achados em virtude das diferenças metodológicas adotadas, a avaliação institucional dos programas é importante para auxiliar a gestão universitária.

Assim, diante da importância dos processos avaliativos em políticas públicas e da escassa investigação acerca do desempenho e da evasão, comparando cotistas e não cotistas, depara-se com o seguinte problema de pesquisa: existe diferença de desempenho e de evasão entre discentes cotistas e não-cotistas do Curso de Graduação em Administração? Visando responder a esta questão, define-se como objetivo de estudo analisar o desempenho acadêmico, a partir do índice de aproveitamento acumulado, e a evasão dos discentes cotistas e não-cotistas do Curso de Graduação em Administração da Universidade Federal de Santa Catarina (UFSC).

\section{ASPECTOS TEÓRICOS}

Além das políticas nacionais, cada instituição, consoante sua autonomia, pode estabelecer políticas próprias de ações afirmativas. Estudo publicado em 2011 identificou que, das 59 instituições federais de ensino superior, 64\% adotavam alguma ação afirmativa. Dessas, 73\% aderiram à reserva de vagas (SOUSA e PORTES, 2011).

O termo ação afirmativa, apesar de pequenas diferenças conceituais a depender do autor, é utilizado de forma bastante uniforme. Para Oliven (2007, p. 30),

refere-se a um conjunto de políticas públicas para proteger minorias e grupos que, em uma determinada sociedade, tenham sido discriminados no passado. A ação afirmativa visa remover barreiras, formais e informais, que impeçam o acesso de certos grupos ao mercado de trabalho, universidades e posições de liderança. Em termos práticos, as ações afirmativas incentivam as organizações a agir positivamente a fim de favorecer pessoas de segmentos sociais discriminados a terem oportunidade de ascender a postos de comando.

$\mathrm{Na}$ Universidade Federal de Santa Catarina, as ações afirmativas foram introduzidas em 2007 em Resolução que define

O "Programa de Ações Afirmativas" da Universidade constitui-se em instrumento de promoção dos valores democráticos, de respeito à diferença $\mathrm{e}$ à diversidade socioeconômica e étnico-racial, mediante a adoção de uma política de ampliação do acesso aos seus cursos de graduação e de estímulo à permanência na Universidade (UFSC, 2007).

A política de cotas que estreou aos ingressantes da UFSC em 2008 não sofreu avaliação formal, tampouco a instituição dispõe de dados divulgados acerca do programa ao longo do tempo. A reserva de vagas, que previa $30 \%$ das vagas do vestibular em cada curso, determinava $20 \%$ para candidatos que cursaram integralmente o ensino fundamental e médio em instituições públicas e $10 \%$ para candidatos autodeclarados negros que cursaram integralmente o ensino fundamental e médio em instituições públicas. Também foi implementado acesso diferenciado a candidatos pertencentes aos povos indígenas (UFSC, 2007).

Além do planejamento e implementação, as políticas públicas precisam ser avaliadas periodicamente, a fim de verificar a viabilidade e continuidade da política diante das transformações ambientais. No entanto, conforme Costa e Castanhar (2003), o histórico brasileiro aponta para o desinteresse de avaliação dos programas públicos. A partir de uma 
conjuntura econômica desfavorável, pressionando por maior eficiência e impacto dos investimentos públicos, a avaliação se apresenta como um instrumento fundamental de gestão.

Ainda assim, para Baggi e Lopes (2011), a avaliação não é mera atividade de coleta e divulgação de dados. Isoladamente ela não provoca as transformações necessárias para a melhoria da qualidade da educação. Ela é um meio para viabilizar mudanças na cultura acadêmica, no trabalho docente, na gestão universitária, nas definições curriculares e de suma importância para a estruturação da educação superior.

Nesse contexto, a expansão do ensino superior brasileiro, a partir do incentivo por programas governamentais, despertou o interesse de avaliar por parte dos estudiosos. Esses programas visam, além de ampliar o acesso e a permanência na educação superior, contribuir para a melhoria do desempenho acadêmico e combater situações de repetência e evasão. Nesse sentido, a UFSC desde 2004, por meio do seu Plano de Desenvolvimento Institucional, demonstra preocupação em relação à análise dos índices de evasão (UFSC, 2004).

Desse modo, a gestão universitária deve apresentar a compreensão básica dos dados a respeito desses fenômenos a fim de analisar possíveis causas e, assim, assimilar os fatos que contribuem para a identificação dos problemas visando adotar medidas institucionais capazes de solucioná-los.

Em relação ao desempenho acadêmico e evasão do ensino superior, estudos com os mais diversos delineamentos metodológicos foram realizados - alguns com recortes metodológicos peculiares. Por isso, buscou-se dados apresentados em estudos quantitativos de metodologia correlata a esta pesquisa.

Os estudos relacionados à evasão apresentam conceitos divergentes, todavia, nem sempre excludentes. O que é unanime em relação ao tema é a consciência de que este fenômeno se torna um problema no sistema educacional.

A evasão estudantil no ensino superior é um problema internacional que afeta o resultado dos sistemas educacionais. As perdas de estudantes que iniciaram, mas não terminaram seus cursos são desperdícios sociais, acadêmicos e econômicos. No setor público, são recursos públicos investidos sem o devido retorno. No setor privado, é uma importante perda de receitas. Em ambos os casos, a evasão é uma fonte de ociosidade de professores, funcionários, equipamentos e espaço físico (SILVA FILHO et al., 2007, p. 642).

Para Bueno (1993), evasão ocorre com a postura ativa do aluno que se desliga do curso sob sua responsabilidade. Ristoff (1995) a entende como o abandono dos estudos, enquanto a migração do estudante para curso diverso é entendida como mobilidade, isto é, a troca de curso, para o autor, não é considerada evasão. A Comissão Especial de Estudos sobre Evasão nas Universidades Públicas Brasileiras (BRASIL, 1996, p. 15) definiu este fenômeno como "a saída definitiva do aluno de seu curso de origem, sem concluí-lo".

Além disso, a referida Comissão (BRASIL, 1996, p. 16) distinguiu o fenômeno em evasão de curso: quando o estudante desliga-se do curso superior em situações diversas tais como: abandono (deixa de matricular-se), desistência (oficial), transferência ou reopção (mudança de curso), exclusão por norma institucional;

evasão da instituição: quando o estudante desliga-se da instituição na qual está matriculado;

evasão do sistema: quanto o estudante abandona de forma definitiva ou temporária o ensino superior (grifo do autor).

Para fins deste estudo, conforme procedimentos metodológicos a seguir, considerou-se evasão o desligamento definitivo do discente do curso de origem, por vontade própria, a partir de sua postura ativa. Vale destacar a dificuldade em generalizar achados relacionados à evasão tendo em vista as peculiaridades de cada metodologia adotada, além da falta de 
unanimidade em relação ao conceito (BRASIL, 1996). Poucos são os estudos quantitativos relacionados ao tema (MOROSINI et al., 2012).

Em pesquisa de Mattar (2009), sobre a evasão nos cursos de Administração de Empresas da Universidade de São Paulo (USP), o erro na escolha do curso, somado ao fato de o evadido descobrir não gostar da área, faz com que esses motivos sejam responsáveis praticamente por $60 \%$ da evasão.

Flores (2017) apresenta um levantamento das causas da evasão apontada pelos autores que abordaram o assunto:

Quadro 1: Possíveis causas de evasão referenciadas na literatura

\begin{tabular}{|c|c|c|}
\hline Autor & \multicolumn{2}{|c|}{ Causas } \\
\hline Adachi (2009) & - Reprovação nos períodos iniciais & - Aspectos financeiros \\
\hline Baggi e Lopes (2010) & - Imaturidade & - Estudantes dependentes das famílias \\
\hline Biazus (2004) & $\begin{array}{l}\text { - Biblioteca insuficiente } \\
\text { - Carga horária semanal } \\
\text { - Currículo inadequado } \\
\text { - Desconhecimento prévio do curso } \\
\text { - Didática ineficiente } \\
\text { - Dificuldade de acompanhamento } \\
\text { - Discriminação racial } \\
\text { - Estar cursando outro curso } \\
\text { - Falta associação teoria/prática } \\
\text { - Falta de Empresa Junior } \\
\text { - Falta de apoio da empresa que trabalha } \\
\text { - Falta de respeito do professor com os } \\
\text { alunos } \\
\text { - Falta de tempo para os estudos } \\
\text { - Greves com prejuízo do calendário escolar } \\
\text { - Inadequação entre os conteúdos } \\
\text { - Inadequação entre os conteúdos } \\
\text { - Inadequado ao trabalho } \\
\text { - Indecisão profissional } \\
\text { - Integração universidade/empresa }\end{array}$ & $\begin{array}{l}\text { - Laboratórios insuficientes } \\
\text { - Mudança de domicílio } \\
\text { - Mudança de estado civil } \\
\text { - Mudança no horário de trabalho } \\
\text { - Não atendeu às expectativas } \\
\text { - Orientação insuficiente } \\
\text { (Coordenadores) } \\
\text { - Pouca ênfase em disciplinas } \\
\text { profissionalizantes } \\
\text { - Pouca motivação dos professores } \\
\text { - Pré-requisitos rígidos } \\
\text { - Pressão familiar } \\
\text { - Programas de apoio para alunos } \\
\text { carentes } \\
\text { - Responsabilidade econômica } \\
\text { - Salas inadequadas } \\
\text { - Problemas de saúde } \\
\text { - Sistema de avaliação das disciplinas é } \\
\text { inadequado }\end{array}$ \\
\hline $\begin{array}{l}\text { Castro e Malacarne } \\
\text { (2011) }\end{array}$ & $\begin{array}{l}\text { - Casamento, filhos } \\
\text { - Responsabilidades com a família } \\
\text { - Deficiência na educação básica } \\
\text { - Métodos de avaliação adotados pela IES } \\
\text { - A localização da IES }\end{array}$ & $\begin{array}{l}\text { - Problemas na leitura, escrita e } \\
\text { interpretação } \\
\text { - A atribuição de notas } \\
\text { - Trabalho versus estudo } \\
\text { - O curso não possui prestígio }\end{array}$ \\
\hline $\begin{array}{l}\text { Goiris, Reinert e } \\
\text { Gubiotti (2012) }\end{array}$ & $\begin{array}{l}\text { - Relacionamento no ambiente familiar } \\
\text { - Deficiência na educação básica }\end{array}$ & $\begin{array}{l}\text { - Faltou orientação vocacional no } \\
\text { momento da escolha } \\
\text { - Baixo compromisso institucional }\end{array}$ \\
\hline Lobo (2012) & $\begin{array}{l}\text { - Aluno não se identifica com o curso } \\
\text { - Mobilidade estudantil }\end{array}$ & $\begin{array}{l}\text { - A educação superior reproduzindo } \\
\text { falhas da educação básica. } \\
\text { - Relação professor-aluno }\end{array}$ \\
\hline Morosini et al. (2012) & $\begin{array}{l}\text { - Escolha precoce e equivocada faz o aluno } \\
\text { alegar que não conhece o curso } \\
\text { - Opção não bem orientada compromete o } \\
\text { nível de compromisso com o curso } \\
\text { - Repetência e reprovação }\end{array}$ & $\begin{array}{l}\text { - Desempenho nas disciplinas } \\
\text { - Currículo rígido } \\
\text { - Ausência de intergação acadêmica }\end{array}$ \\
\hline Pereira Junior (2012) & - Gênero como causa da evasão & $\begin{array}{l}\text { - Se a escolha do curso foi muito } \\
\text { precoce }\end{array}$ \\
\hline Rios (2016) & $\begin{array}{l}\text { - Problemas financeiros } \\
\text { - Insatisfação com a IES } \\
\text { - Insatisfação com o curso } \\
\text { - Problemas de saúde } \\
\text { - Transferência }\end{array}$ & $\begin{array}{l}\text { - Assistência estudantil } \\
\text { - Distância } \\
\text { - Estrutura da IES } \\
\text { - Mercado de trabalho } \\
\text { - Família }\end{array}$ \\
\hline Silva Filho et al. (2009) & $\begin{array}{l}\text { - Deficiência do ensino básico } \\
\text { - Período inicial do curso considerado de }\end{array}$ & $\begin{array}{l}\text { - Os estudantes não se adequam à } \\
\text { metodologia do curso }\end{array}$ \\
\hline
\end{tabular}




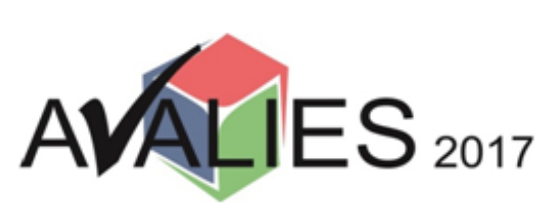

$3^{\circ}$ Simpósio Avaliação da Educação Superior

05 e 06 de setembro de 2017

Florianópolis - SC-Brasil

ISBN: $978-85-68618-04-2$

\begin{tabular}{|l|l|l|}
\hline & $\begin{array}{l}\text { risco e com grandes chances de evasão } \\
- \text { Desempenho nas disciplinas }\end{array}$ & $\begin{array}{l}\text { Aulas teóricas e disciplinas } \\
\text { complexas } \\
\text { - Currículo rígido das universidades }\end{array}$ \\
\hline
\end{tabular}

Fonte: Elaborado a partir de Flores (2017)

De acordo com Silva Filho et al. (2007), a taxa de evasão brasileira nos cursos superiores não difere muito das taxas internacionais. Seu estudo, baseado nos dados disponibilizados pelo Instituto Nacional de Estudos e Pesquisas Educacionais Anísio Teixeira (INEP), identificou uma evasão anual média nacional, para os anos entre 2000 e 2005, de $22 \%$. "A evasão anual nas IES públicas tem oscilado em torno dos $12 \%$, variando entre 9 e $15 \%$ no período, enquanto as IES privadas mostram uma oscilação em torno de $26 \%$ " (SILVA FILHO et al., 2007, p. 647). Vale destacar que essa taxa média inclui universidades, centros universitários e faculdades. Quanto às universidades, isoladamente, a taxa de evasão para o período foi de $19 \%$.

Nesse mesmo estudo, os autores buscaram correlacionar os índices de evasão com a demanda em alguns cursos. Eles identificaram uma correlação negativa, assim, quanto maior a concorrência entre candidato/vaga nos concursos vestibulares, menores são os índices de evasão verificados (SILVA FILHO et al., 2007).

Um estudo realizado na Universidade de Brasília (UnB) identificou que os alunos cotistas apresentam evasão menor em comparação aos alunos não cotistas, ou seja, "os cotistas se evadem menos que os não-cotistas, exatamente o oposto do que prediziam algumas das críticas ao sistema de reserva de vagas (CARDOSO, 2008, p. 99). Entretanto, esse fenômeno é de complexa análise por haver diversidade no comportamento da evasão por área de conhecimento, por curso, opção (bacharelado ou licenciatura) e de acordo com o perfil do aluno (GILIOLI, 2016). No entanto, no estudo de Cardoso (2008), essas diferenciações não foram analisadas. Além disso, a "incidência de evadidos também varia conforme a etapa do curso, sendo mais comum no primeiro ano, mas também com relativa intensidade no segundo ano" (GILIOLI, 2016, p. 49).

Mendes Junior (2013) também identificou que, na Universidade do Estado do Rio de Janeiro (UERJ), a evasão dos não cotistas é superior a dos discentes cotistas. 15,6\% dos não cotistas abandonaram a universidade no primeiro ano da graduação enquanto que os cotistas apresentaram uma evasão cerca de três vezes menor $(5,8 \%)$. O autor destacou a importância de a instituição também se preocupar com a permanência dos alunos não contemplados com ingresso diferenciado. A maior evasão dos não cotistas foi detectada no curso de oceanografia, apresentando $69 \%$ de desistência no primeiro ano; para os cotistas, o curso de química apresentou maior abandono (26\%).

Ainda na UERJ, a diferença entre os dois grupos cai quando analisada a evasão entre o segundo e o quarto ano de graduação, corroborando com os achados de Gilioli (2016). Contudo, ela se mantém favorável aos cotistas, que continuam apresentando menores taxas de evasão - 32,8\% contra quase $40 \%$ dos não cotistas. Destaca-se o fato de a evasão ser maior, para primeiro ano de graduação, nos cursos considerados de alta dificuldade (MENDES JUNIOR, 2013).

Em outro estudo relacionado à evasão, as autoras consideraram também a mobilidade para a definição de evasão e para composição da amostra. Os cursos de ciências da saúde apresentaram o menor índice - 19,6\%, sendo a maior evasão identificada nos cursos de ciências exatas e da terra, representando $58,8 \%$. Isoladamente, o curso com maior índice de evasão foi Licenciatura em Física $(83,2 \%)$. A média de evasão encontrada na instituição foi de 38,2\% - bastante divergente dos achados de Silva Filho (2007) (DAVOK e BERNARD, 2016). 
Em relação ao desempenho acadêmico, no estudo quantitativo de Peixoto et al. (2016), quando os alunos são comparados de forma conjunta, identificou-se uma diferença estatisticamente significativa entre o desempenho dos cotistas e não cotistas. Estes apresentam um coeficiente de rendimento $6,81 \%$ superior ao dos cotistas. Tal resultado corrobora com os achados de Mendes Junior (2013) que identificou uma diferença de rendimento 6,5\% superior para os não cotistas. Entretanto, "apesar de obterem um resultado inferior em termos de notas médias, os cotistas estão se formando a taxas maiores que o grupo não beneficiado" (MENDES JUNIOR, 2013, p. 56).

Peixoto et al. (2016) identificaram uma redução da diferença no desempenho acadêmico quando comparado os escores dos melhores cotistas com os dos melhores não cotistas, isto é, os desempenhos se aproximam. Quando analisado em função do curso, os autores constataram que a diferença se mostra de forma complexa e multifacetada; a depender do curso, a diferença pode ser irrelevante, bastante expressiva, ou ainda, se inverter. $\mathrm{O}$ desempenho dos cotistas é superior em cursos predominantemente das áreas de artes e humanidades e nos cursos de baixa ou média demanda social; já os não cotistas apresentam melhor desempenho acadêmico nos cursos das áreas de exatas e biológicas e, em sua maioria, cursos de alta demanda social.

Em estudo realizado por Queiroz et al. (2015) na Universidade Federal de Uberlândia (UFU), também foi identificado uma defasagem entre o desempenho dos cotistas e não cotistas. O rendimento dos candidatos da ampla concorrência (os não beneficiados por ingresso diferenciado) foi significativamente maior quando comparado aos discentes ingressantes pelo programa de ação afirmativa da UFU e pela lei nacional de cotas.

Os resultados apontados não devem ser indistintamente generalizados, tendo em vista as peculiaridades metodológicas. Porém, conforme demonstrado, as evidências disponíveis nas pesquisas citadas apontam de forma consistente para uma lacuna entre desempenho acadêmico e evasão; enquanto os cotistas apresentam maior diplomação por evadirem em menor grau eles, em média, mostram-se com menor desempenho acadêmico. Por outro lado, os não cotistas atingem maior desempenho, porém com menor índice de diplomação. Assim, resta compreender a dinâmica desses fenômenos para subsidiar a gestão universitária.

\section{ASPECTOS METODOLÓGICOS}

Em relação ao caminho metodológico adotado, esta pesquisa foi delineada sob dois critérios básicos: quanto aos fins, trata-se de uma pesquisa de natureza descritiva, e quanto aos meios, classifica-se como estudo bibliográfico, documental e estudo de caso (MARCONI, LAKATOS, 2003; VERGARA, 2010). Para cumprir sua trajetória, utilizou-se a abordagem quantitativa.

Os dados secundários utilizados foram disponibilizados pela Superintendência de Governança Eletrônica e Tecnologia da Informação e Comunicação (SeTIC), de forma censitária, a partir da base do Sistema de Controle Acadêmico da Graduação (CAGR). Os parâmetros (filtros) aplicados no sistema para a coleta de dados foram: ingressantes no curso de Administração (diurno e noturno) entre 2008 e 2012, forma de ingresso, situação acadêmica e índice de aproveitamento acumulado (IAA). Os dados foram coletados no primeiro semestre de 2017.

A delimitação do período justifica-se por ser a fase não compulsória da política de cotas. Assim, pode-se avaliar a política institucional de reserva de vagas na UFSC de forma objetiva a partir dos dados quantitativos. Além disso, alicerçado na avaliação preliminar dessa ação afirmativa, pode-se extrair informações capazes de beneficiar e incrementar o programa na instituição. 
Com o propósito de contribuir para a discussão e aprofundamento do tema, bem como para servir de fonte para pesquisadores e/ou instituições governamentais, este estudo de caráter preliminar estabeleceu para análise o curso de Administração de forma aleatória.

Para este período, a forma de ingresso apresentada no CAGR é dividida entre classificação geral, escola pública e autodeclarados negros. Assim, os ingressantes a partir das categorias escola pública e autodeclarados negros abrangem o grupo dos cotistas. Importante destacar que esta classificação não inclui os acadêmicos oriundos de transferências, convênios, Sistema de Seleção Unificada (Sisu) ou outra forma que não seja o concurso vestibular.

Em relação à situação acadêmica, o sistema segrega os discentes nas seguintes categorias: abandono, desistência, eliminado, formado, jubilado, regular, trancado, transferido e troca de curso.

Conforme situação acadêmica, os discentes serão agregados para apurar as análises. As categorias de alunos regulares e com matrícula trancada foram apresentadas como situação acadêmica "Ativo". Os evadidos são a soma dos acadêmicos cadastrados na categoria abandono e desistência ${ }^{1}$. Por fim, os acadêmicos classificados em "Mobilidade" representam a reunião dos transferidos e dos que realizaram troca de curso ${ }^{2}$. Aos discentes classificados como formado, jubilado e falecido não foram utilizadas novas categorias já que sua nomenclatura, além de autoexplicativa, não comporta agregação.

Quanto ao significado dos termos empregados, entende-se por IAA o quociente entre o somatório de pontos obtidos e a carga horária matriculada (UFSC, 1997). Em relação a este índice, cabe destacar que o filtro aplicado no CAGR só contempla IAA superior à zero (0) para que os casos de reprovação por falta e ausência de notas no sistema não influenciem o índice de desempenho.

Para prognóstico da evasão, considerou-se neste estudo as seguintes categorias de situação acadêmica: abandono e desistência. Portanto, utilizou-se o conceito de evasão como desligamento definitivo do discente do curso de origem, por vontade própria, a partir de sua postura ativa. Assim, os discentes com matrícula trancada não foram concebidos como evasão devido à possibilidade de retorno; as categorias "transferido" e "troca de curso" foram compreendidas como mobilidade.

A análise dos dados foi realizada por meio do software Excel, utilizando-se estatística descritiva. Salienta-se que, para a realização da pesquisa, presume-se a validade dos dados fornecidos pela SeTIC, responsável pela integridade dos dados no CAGR. Ademais, julga-se que os dados são confiáveis e livres de erros no registro em cada instância administrativa responsável.

\section{ANÁLISE DOS RESULTADOS}

Após aplicação da metodologia destacada na seção anterior, atingiu-se uma população de 942 ingressantes no curso de Administração da UFSC entre 2008 e 2012 por meio do concurso vestibular. Os acadêmicos estavam distribuídos entre o curso diurno $(\mathrm{N}=473)$ e noturno ( $\mathrm{N}=469)$. Para o período, houve predominância de ingressantes do gênero masculino, perfazendo $58,49 \%$ da população (551 discentes).

\footnotetext{
${ }^{1}$ Abandono ocorre quando o acadêmico não desiste formalmente do curso, porém não mantém vínculo com a instituição por meio de matrícula e desistência é a situação formalizada de renúncia do seu vínculo com a UFSC.

${ }^{2}$ Transferido é o estudante que finaliza seu vínculo com a UFSC e realiza sua matrícula em outra IES e troca de curso ocorre quando o acadêmico modifica seu vínculo com a UFSC alterando seu curso de origem.
} 
A distribuição dos discentes por tipo de ingresso e gênero é apresentada na tabela 1. Em virtude da legislação vigente para o período que reservava $30 \%$ das vagas aos estudantes autodeclarados negros e advindos de escolas públicas, o predomínio de acesso ao curso de Administração da UFSC ocorreu por meio da ampla concorrência (classificação geral). Assim, maior parte dos discentes $(73,14 \%)$ não usufruiu de ingresso diferenciado.

Tabela 1 - Distribuição dos discentes do curso de Administração, ingressantes na UFSC entre 2008 e 2012, por tipo de ingresso e gênero.

\begin{tabular}{lccc}
\hline Tipo de ingresso & Feminino & Masculino & Total Geral \\
\hline Ampla concorrência & $264(38,32)$ & $425(61,68)$ & $689(100)$ \\
Autodeclarado negro & $34(52,31)$ & $31(47,69)$ & $65(100)$ \\
Escola pública & $93(49,47)$ & $95(50,53)$ & $188(100)$ \\
Total discentes & $\mathbf{3 9 1}(\mathbf{4 1 , 5 1 )}$ & $\mathbf{5 5 1}(\mathbf{5 8 , 4 9 )}$ & $\mathbf{9 4 2}(\mathbf{1 0 0})$
\end{tabular}

NOTA: os números entre parênteses correspondem às percentagens em relação ao total da linha. Fonte: Sistema de Controle Acadêmico da Graduação (CAGR, 2017).

\subsection{AVALIAÇÃO DA EVASÃO}

Em relação aos cotistas, apesar de a política de ações afirmativas da UFSC destinar $30 \%$ das vagas a eles - $20 \%$ para escolas públicas e 10\% para autodeclarados negros (UFSC, 2007) -, o preenchimento se mostrou aquém da reserva de vagas (oferta versus matrícula). Os discentes cotistas representaram 26,86\% dos ingressantes, isto é, mais de $3 \%$ das vagas reservadas ao ingresso diferenciado foram preenchidas por meio da classificação geral. Na categoria escola pública, as vagas ofertadas foram quase integralmente preenchidas $(19,96 \%)$. Porém, a categoria de autodeclarados negros ficou abaixo do destinado, preenchendo apenas $6,90 \%$ das vagas. Tragtenberg (2010) presumiu que o não preenchimento das vagas reservadas na UFSC durante esta política institucional de ações afirmativas ocorreu devido ao aumento das notas mínimas no concurso vestibular.

Esses dados relacionados à ocupação das vagas destinadas aos cotistas reforçam os achados do estudo realizado por Azevedo et al. (2011). Os autores avaliaram o preenchimento das vagas destinadas aos cotistas na UFSC, para o período de 2008 a 2010, e demonstraram que as vagas reservadas aos provenientes de escolas públicas têm sido preenchidas em quase sua totalidade. Entretanto, as vagas reservadas aos autodeclarados negros apresentam descompasso entre oferta e matrícula, "uma vez que os candidatos autodeclarados negros acabam por não alcançar a nota mínima exigida no concurso vestibular" (AZEVEDO et al., 2011, pg. 9).

Para analisar a evasão dos discentes, optou-se por uma distribuição conjunta entre tipo de ingresso e situação acadêmica, conforme Tabela 2.

Observa-se que a evasão da população atingiu $22,82 \%$ do total de ingressantes no período, sendo que o grupo com o maior percentual de evasão foi o segmento de discentes cotistas autodeclarados negros - 30,77\% dos ingressantes autodeclarados negros evadiram do curso.

Aos ingressantes no curso por meio da ampla concorrência (classificação geral), a evasão correspondeu a $22,79 \%$, enquanto que aos ingressantes de escolas públicas foi de $20,21 \%$. Entretanto, quando se analisa os cotistas agregando-os em um único grupo, observase uma taxa de evasão de $22,92 \%$ do total de ingressantes cotistas - valor ligeiramente maior em comparação aos discentes da ampla concorrência. 
Portanto, entre os discentes cotistas e não cotistas, a maior taxa de evasão no curso de Administração da UFSC durante a política institucional de reserva de vagas ocorreu no grupo de cotistas, isto é, aos ingressantes que contaram com entrada diferenciada no ensino superior. Apesar de pequena diferença entre os grupos, esses dados não corroboram com os achados de Cardoso (2008), Dias, Theóphilo e Lopes (2010) e Mendes Junior (2013).

Tabela 2 - Distribuição dos discentes do curso de Administração, ingressantes na UFSC entre 2008 e 2012, entre tipo de ingresso e situação acadêmica.

\begin{tabular}{ccccc}
\hline Situação acadêmica & Ampla concorrência & Autodeclarado negro & Escola Pública & Total \\
\hline Ativo & $138(20,03$ & $19(29,23)$ & $51(27,13)$ & $208(22,08$ \\
Evadido & $157(22,79)$ & $20(30,77)$ & $38(20,21)$ & $215(22,82)$ \\
Falecido & $1(0,15)$ & $0(0,00)$ & $0(0,00)$ & $1(0,11)$ \\
Formado & $371(53,85)$ & $25(38,46)$ & $97(51,60)$ & $493(52,34)$ \\
Jubilado & $1(0,15)$ & $0(0,00)$ & $0(0,00)$ & $1(0,11)$ \\
Mobilidade & $21(3,05)$ & $1(1,54)$ & $2(1,06)$ & $24(2,55)$ \\
\hline Total Geral & $\mathbf{6 8 9}(\mathbf{1 0 0})$ & $\mathbf{6 5}(\mathbf{1 0 0})$ & $\mathbf{1 8 8}(\mathbf{1 0 0})$ & $\mathbf{9 4 2}(\mathbf{1 0 0})$ \\
\hline
\end{tabular}

NOTA: os números entre parênteses correspondem às percentagens em relação ao total da coluna. Fonte: Sistema de Controle Acadêmico da Graduação (CAGR, 2017).

Alguns autores, como por exemplo Cardoso (2008) e Azevedo et al. (2011), supõem que menores taxas de evasão dos cotistas estão atribuídas a uma maior valorização do acesso ao ensino superior e ao maior poder de enfrentamento de adversidades. Contudo, para o curso de Administração da UFSC, essa premissa parece não ser verdadeira.

\subsection{EVASÃO POR GÊNERO}

Em relação ao gênero, dos 215 discentes evadidos, 143 eram do gênero masculino. Desse modo, 66,51\% dos acadêmicos que desistiram ou abandonaram o curso de Administração da UFSC, entre 2008 e 2012, eram homens. Dias, Theóphilo e Lopes (2010) encontraram igual manifestação no curso de Ciências Contábeis da Universidade Estadual de Montes Claros.

Uma pesquisa realizada na Universidade do Estado de Santa de Santa Catarina (UDESC), demonstrou que a evasão nos cursos de Ciências Sociais Aplicadas ultrapassa 37\% (DAVOK; BERNARD, 2016). Entretanto, os autores consideraram para o cálculo da evasão as transferências e as trocas de curso - entendida aqui como mobilidade. Por isso, reitera-se a dificuldade em exercer comparações tendo em vista as diferentes metodologias e concepções aplicadas. Contudo, o estudo identificou para o curso de Administração uma taxa de evasão de $17,7 \%$ para o período de 2008 a 2010.

\subsection{Desempenho acadêmico}

Ainda a respeito da evasão, avaliou-se sua relação com o desempenho acadêmico dos grupos cotistas e não cotistas, conforme Tabela 3. Os discentes cotistas evadidos apresentaram IAA médio de 4,41 (desvio padrão 1,68) e os não cotistas apresentaram IAA médio de 4,83 (desvio padrão 2,32 - representando uma maior dispersão). Logo, os acadêmicos evadidos ingressantes por meio da classificação geral apresentaram índice de aproveitamento acumulado superior ao dos cotistas.

Quando os discentes evadidos são comparados à população (IAA médio 6,61 e desvio padrão 1,83, conforme Tabela 4), nota-se uma lacuna ainda maior entre as performances. Entretanto, é imperativo destacar o caráter exploratório desta pesquisa, predominantemente 
descritiva, apresentando-se como um levantamento preliminar. Assim, não se pode inferir se o desempenho acadêmico é fator determinante para a evasão.

Tabela 3 - Índice de aproveitamento acumulado (IAA) médio dos discentes cotistas e não cotistas evadidos do curso de Administração da UFSC entre 2008 e 2012.

\begin{tabular}{lccc}
\hline Tipo de ingresso & N & Média do IAA & Desvio Padrão \\
\hline Ampla concorrência & $\mathbf{1 5 7}$ & $\mathbf{4 , 8 3}$ & $\mathbf{2 , 3 2}$ \\
Cotistas & $\mathbf{5 8}$ & $\mathbf{4 , 4 1}$ & $\mathbf{1 , 6 8}$ \\
$\quad$ Autodeclarado negro & 20 & 4,60 & 1,45 \\
Escola Pública & 38 & 4,31 & 1,80 \\
Total Geral & $\mathbf{2 1 5}$ & $\mathbf{4 , 7 1}$ & $\mathbf{2 , 1 7}$ \\
\hline
\end{tabular}

Fonte: Sistema de Controle Acadêmico da Graduação (CAGR, 2017).

O Gráfico 1 ilustra a comparação entre o desempenho dos discentes evadidos e dos formados. Observa-se que o IAA médio dos cotistas formados do segmento escola pública é ligeiramente superior ao IAA dos formados ingressantes por meio da classificação geral. Ou seja, não se pode avaliar como uniforme o desempenho dos cotistas, visto que os oriundos da escola pública conseguiram ter desempenho ligeiramente superior aos ingressantes através do acesso universal, mas os auto declarados negros não. A redução de diferença entre os grupos na conclusão da graduação sugere que o desempenho dos cotistas e não cotistas se aproxima no final do curso e permite inferir que a metodologia adotada no curso auxilia a reduzir diferenças pré-existentes. $\mathrm{O}$ mesmo não pode ser considerado com relação ao desempenho acadêmico dos discentes evadidos, onde há uma variação maior entre cotistas e não cotistas.

Não se pode afirmar ou atribuir a evasão dos discentes de Administração da UFSC ao desempenho acadêmico, entretanto, observa-se que o desempenho dos formados é bastante superior ao dos evadidos.

Gráfico 1 - Índice de aproveitamento acumulado (IAA) médio entre discentes evadidos e formados do curso de Administração da UFSC entre 2008 e 2012.

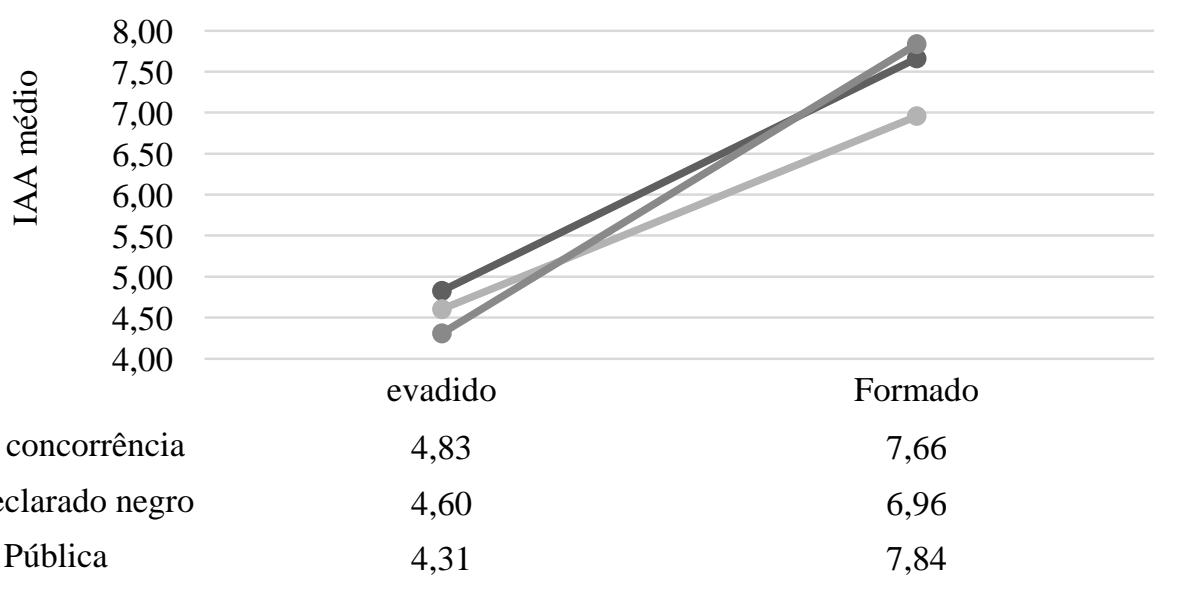

A partir da análise do IAA, conforme Tabela 4, a seguir, observa-se que o desempenho acadêmico dos discentes ingressantes por meio da ampla concorrência é superior quando comparado aos discentes cotistas. A maior diferença é encontrada para o segmento de cotistas autodeclarados negros.

Tabela 4 - Índice de aproveitamento acumulado (IAA) médio dos discentes cotistas e não cotistas do curso de Administração da UFSC entre 2008 e 2012. 


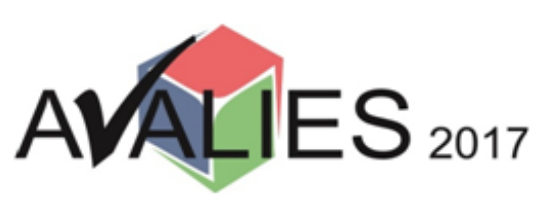

$3^{\circ}$ Simpósio Avaliação da Educação Superior

05 e 06 de setembro de 2017

Florianópolis - SC-Brasil

ISBN: 978-85-68618-04-2

\begin{tabular}{lccc}
\hline Tipo de ingresso & N & Média do IAA & Desvio Padrão \\
\hline Ampla concorrência & $\mathbf{6 8 9}$ & $\mathbf{6 , 7 1}$ & $\mathbf{1 , 8 2}$ \\
Cotistas & $\mathbf{2 5 3}$ & $\mathbf{6 , 3 3}$ & $\mathbf{1 , 8 5}$ \\
Autodeclarado negro & 65 & 5,60 & 1,62 \\
Escola Pública & 188 & 6,59 & 1,86 \\
\hline Total Geral & $\mathbf{9 4 2}$ & $\mathbf{6 , 6 1}$ & $\mathbf{1 , 8 3}$ \\
\hline
\end{tabular}

Fonte: Sistema de Controle Acadêmico da Graduação (CAGR, 2017).

Quando a análise não distingue o segmento de cota do qual ocorreu o ingresso, observa-se um IAA médio de 6,33 (desvio padrão de 1,85) para os cotistas. Portanto, a partir da análise conjunta dos tipos de ingresso, os cotistas apresentaram desempenho ligeiramente menor quando comparados aos ingressantes da classificação geral (ampla concorrência). Peixoto et al. (2016) também identificaram uma defasagem entre o desempenho acadêmico de cotistas e não cotistas na Universidade Federal da Bahia.

\subsection{GÊNERO E O DESEMPENHO ACADÊMICO}

O maior IAA médio no curso de Administração da UFSC apresenta o seguinte perfil, conforme ilustrado na Tabela 5: mulheres ingressantes por meio da ampla concorrência. Para todos os tipos de ingresso, o gênero feminino apresentou maior desempenho (com os menores desvio padrão, indicando menor dispersão nos dados).

Tabela 5 - Índice de aproveitamento acumulado (IAA) médio por gênero e tipo de ingresso dos discentes cotistas e não cotistas do curso de Administração da UFSC entre 2008 e 2012.

\begin{tabular}{lccccc}
\hline Gênero & Tipo de ingresso & N & Média do IAA & Desvio Padrão & Terceiro quartil \\
\hline \multirow{4}{*}{ Feminino } & Ampla concorrência & 264 & 7,29 & 1,59 & 8,27 \\
& Autodeclarado negro & 34 & 6,01 & 1,51 & 7,35 \\
& Escola pública & 93 & 7,23 & 1,38 & 8,18 \\
& Feminino Total & $\mathbf{3 9 1}$ & $\mathbf{7 , 1 6}$ & $\mathbf{1 , 5 7}$ & $\mathbf{8 , 2 2}$ \\
\hline \multirow{4}{*}{ Masculino } & Ampla concorrência & 425 & 6,36 & 1,86 & 7,64 \\
& Autodeclarado negro & 31 & 5,16 & 1,59 & 6,55 \\
& Escola pública & 95 & 5,95 & 2,04 & 7,67 \\
& Masculino Total & $\mathbf{5 5 1}$ & $\mathbf{6 , 2 2}$ & $\mathbf{1 , 9 0}$ & $\mathbf{7 , 6 0}$ \\
\hline
\end{tabular}

Fonte: Sistema de Controle Acadêmico da Graduação (CAGR, 2017).

Quando analisada a parte superior da população (terceiro quartil), identifica-se uma redução na diferença entre os desempenhos - tanto para o gênero masculino quanto para o feminino. Esses dados sugerem que o desempenho dos melhores acadêmicos cotistas se aproxima do desempenho dos melhores não cotistas. Tal resultado corrobora os achados de Peixoto et al. (2016) e Guimarães, Costa e Almeida Filho (2011).

Em linhas gerais, os não cotistas, ou seja, os discentes ingressantes por meio da ampla concorrência do curso de Administração da UFSC, apresentaram um desempenho acadêmico (IAA médio) superior ao dos discentes cotistas, mas tal superiodade é amenizada quando ocorre a segmentação entre autodeclarados negros e egresssos da escola pública, onde o IAA 
dos egressos da escola pública é muito próximo da ampla concorrência, em especial no gênero feminino. No tocante à evasão, os acadêmicos ingressantes por meio das cotas do segmento escola pública são os que apresentam o menor abandono e desistência do curso.

\section{CONSIDERAÇÕES FINAIS}

Esta pesquisa apresentou como objetivo analisar o desempenho acadêmico, a partir do índice de aproveitamento acumulado, e a evasão dos discentes cotistas e não-cotistas do curso de Administração da UFSC durante o período da política institucional de reserva de vagas (2008 a 2012). Caracteriza-se por ser um levantamento preliminar, predominantemente descritivo. A comparação entre os grupos deve ser compreendida como um fenômeno complexo e este estudo, apesar de informativo, não explorou características específicas de cada grupo.

Os resultados sugerem que existe diferença entre os grupos cotistas e não cotistas em relação à evasão e ao desempenho acadêmico no curso de Administração da UFSC. O grupo dos cotistas exibe um IAA médio relativamente menor - tendência identificada em outros estudos (PEIXOTO et al., 2016; QUEIROZ et al., 2015).

Os ingressantes por reserva de vagas (cotistas) apresentam, em relação à evasão, um maior índice de abandono e desistência. Destaque-se os cotistas autodeclarados negros que apresentam a maior taxa de evasão e o menor IAA médio do curso. Dessa forma, são os cotistas do segmento escola pública que elevam a média do IAA e abaixam a média de evasão do grupo cotista em comparação aos ingressantes da ampla concorrência, destacando a necessidade de uma análise segmentada da política de cotas adotada pela instituição.

As qualidades de que se reveste o estudo não excluem, no entanto, seu caráter preliminar. As análises quantitativas apresentadas necessitam ser estendidas a outros cursos, complementadas e correlacionadas. Matérias relacionadas ao conceito e à metodologia de cálculo para a evasão na educação superior no Brasil compõem temática ainda indefinida e, por isso, de difícil generalização. O mesmo ocorre com relação às análises de desempenho acadêmico e das políticas de ações afirmativas.

Avaliar o desempenho e a evasão no ensino superior faz parte da gestão universitária a fim de maximizar o uso dos recursos disponíveis. Entretanto, mesmo expandindo a observação para a totalidade de cursos da IES, não há um índice prévio de desempenho acadêmico ou evasão que possa servir como parâmetro razoável de uma gestão acadêmica.

Sugere-se pesquisas futuras para o aprofundamento do tema em outros cursos, correlacionando os resultados da instituição, e com outras IES. Além disso, cumpre destacar que os dados levantados merecem interpretação e análise contextualizada a fim de identificar os fatores motivadores dos fenômenos para que a gestão universitária disponha de subsídios para a tomada de decisão.

\section{REFERÊNCIAS}

ADACHI, A. A. C. T. Evasão e evadidos nos cursos de graduação da Universidade Federal de Minas Gerais. 2009. 214 p. Dissertação de Mestrado, Universidade Federal de Minas Gerais, Programa de Pós-graduação em Educação, 2009.

AZEVEDO, M. I. N. et al. O acesso à UFSC à luz da teoria da gestão social: uma perspectiva das cotas e da evasão. In: XI COLÓQUIO INTERNACIONAL SOBRE GESTÃ̃ UNIVERSITÁRIA NA AMÉRICA DO SUL, 2011, Florianópolis. Anais eletrônicos... Florianópolis, INPEAU, 2011. Disponível em: <http://repositorio.ufsc.br/xmlui/handle/123456789/30818>. Acesso em: 6 dez. 2016. 
BAGGI, C. A. S.; LOPES, D. A. Evasão e avaliação institucional do ensino superior: uma discussão
bibliográfica. Avaliação (Campinas), Sorocaba, SP, v. 16, n. 2, p. 355-374, jul. 2011.

BIAZUS, C. A. Sistema de fatores que influenciam o aluno a evadir-se dos cursos de graduação na UFSM e na UFSC: um estudo no curso de ciências contábeis. 2004. Tese de Doutorado, Universidade Federal de Santa Catarina, Programa de Pós-graduação em Engenharia de Produção, 2004.

BRASIL. Ministério da Educação. Secretaria de Educação Superior. Comissão Especial de Estudos sobre a Evasão nas Universidades Públicas Brasileiras. Diplomação, retenção e evasão nos cursos de graduação em instituições de ensino superior públicas. Brasília: ANDIFES/ABRUEM/SESu/MEC, 1996. 35 p.

BUENO, J. L. A Evasão de Alunos. Jornal da USP, São Paulo, USP, 14 a 20 de junho de 1993.

CARDOSO, C. B. Efeitos da política de cotas na Universidade de Brasília: uma análise do rendimento e da evasão. Março 2008. 134 f. Dissertação (Mestrado em Educação) - Faculdade de Educação, Universidade de Brasília, Brasília. 2008.

CASTRO, L. P. V. de; MALACARNE, Vilmar. Conceituando a evasão escolar no Brasil. In: ENCONTRO INTERNACIONAL DE PRODUÇÃO CIENTÍFICA (EPCC), 7, 2011, Maringá. Anais eletrônicos... Maringá, CESUMAR, 2011. Disponível em $<$ http://www.cesumar.br/prppge/pesquisa/epcc2011/anais/luciana_paula_vieira_castro1.pdf. Acesso em 14 maio 2017.

COSTA, F. L.; CASTANHAR, J. C. Avaliação de programas públicos: desafios conceituais e metodológicos. Revista de Administração Pública, Rio de Janeiro, v. 37, n. 5, p. 969-992, set.out. 2003.

DAVOK, D. F.; BERNARD, R. P. Avaliação dos índices de evasão nos cursos de graduação da Universidade do Estado de Santa Catarina - UDESC. Avaliação (Campinas), Sorocaba, SP, v. 21, n. 2, p. 503-521, jul. 2016.

DIAS, E. C. M.; THEÓPHILO, C. R.; LOPES, M. A. S. Evasão no ensino superior: estudo dos fatores causadores da evasão no curso de Ciências Contábeis da Universidade Estadual de Montes Claros Unimontes - MG. In: CONGRESSO USP DE INICIAÇÃO CIENTÍFICA EM CONTABILIDADE, 7., São Paulo. Anais... São Paulo: Êxito, 2010.

FLORES, Evandro Gomes. Modelo de gestão do conhecimento para acompanhamento de tendência à evasão em cursos de graduação presencial. 2017. Dissertação de Mestrado, Universidade Federal de Santa Maria, Programa de Pós-graduação em Engenharia de Produção, 2017.

GILIOLI, R. S. P. Evasão em Instituições Federais de Ensino Superior no Brasil: expansão da rede, SISU e desafios. 2016. Câmara dos Deputados. Disponível em: $<$ http://www2.camara.leg.br/documentos-e-pesquisa/publicacoes/estnottec/areas-daconle/tema11/2016_7371_evasao-em-instituicoes-de-ensino-superior_renato-gilioli>. Acesso em: 10 nov. 2016.

GOIRIS, M. C. REINERT, J. N.; GUBIOTTI, B. Influência da falta de informação na evasão escolar na percepção dos coordenadores de curso de graduação do CCHS/UFMS. IN: COLÓQUIO INTERNACIONAL SOBRE GESTÃO UNIVERSITÁRIA NAS AMÉRICAS, 12. Veracruz (MEX). Anais... Veracruz (MEX): INPEAU, 2012. 
GUIMARÃES, A. S.; COSTA, L.; ALMEIDA FILHO, N. Inclusão social nas universidades brasileiras: o caso da UFBA In: AS CORES DA DESIGUALDADE. Belo Horizonte: Fino Traço, 2011. v. 1. p. 19-41.

INSTITUTO NACIONAL DE ESTUDOS E PESQUISAS EDUCACIONAIS ANÍSIO TEIXEIRA INEP. Evolução da Educação Superior: Graduação 1991/2007. Brasília: INEP. Disponível em: <http://portal.inep.gov.br/web/censo-da-educacao-superior/evolucao-1980-a-2007>. Acesso em: 20 out. 2016.

INEP, 2006.

Modelos Institucionais de Ensino Superior. In: EDUCAÇÃO EM DEBATE. Brasília:

LOBO, M. B. de C. M. Panorama da evasão no ensino superior brasileiro: aspectos gerais das causas e soluções. ABMES Cadernos. Brasilia, set./dez. 2012.

MARCONI, M. A.; LAKATOS, E. M. Fundamentos de metodologia científica. 5. ed. São Paulo: Atlas, 2003.

MATTAR, F. N. Avaliação do ensino de administração: modelo conceitual e aplicação, 2009. Disponível em: $<$ http//fauze.com.br $>$. Acesso em: 10 jan. 2017.

MENDES JUNIOR, A. A. F. Três ensaios sobre ações afirmativas no ensino superior brasileiro: acesso, progressão e simulações de diferentes políticas de cotas para a Universidade do Estado do Rio de Janeiro. Dissertação (Pós-Graduação em Ciências Econômicas) - Universidade Federal Fluminense, Niterói, 2013. Disponível em: <http://www.proac.uff.br/cede/sites/default/files/MonografiaAlvaro_Mendes.pdf > Acesso em: 14 nov. 2016.

MIELKI, A. C.; BIONDI, A.; HAMMES, D.; ROSSI, A. Cotas avançam nas universidades públicas de norte a sul do país. Revista Adusp, julho 2008.

MOROSINI, M. C.; CASARTELLI, A. O.; SILVA, A. C. B.; SANTOS, B. S.; SCHMITT, R. E.; GESSINGER, R. M. A evasão na educação superior no Brasil: uma análise da produção de conhecimento nos periódicos Qualis entre 2000-2011. Pontífícia Universidade Católica do Rio Grande do Sul - PUCRS, Faculdade de Educação - FACED, Porto Alegre, Rio Grande do Sul, 2012. Disponível em: <http://hdl.handle.net/10923/8762> Acesso em: 11 nov. 2016.

OLIVEN, A. C. Ações afirmativas, relações raciais e política de cotas nas universidades: uma comparação entre os Estados Unidos e o Brasil. Educação, Porto Alegre, 61, n. 1, 2007. 29-51.

PASCUCI, L.; MEYER JUNIOR, V.; MAGIONI, B.; SENA, R. Managerialism na gestão universitária: implicações do planejamento estratégico segundo a percepção de gestores de uma universidade pública. Revista GUAL, Florianópolis, v. 9, n. 1, p. 37-59, jan. 2016.

PEIXOTO, A. L. A. et al. Cotas e desempenho acadêmico na UFBA: um estudo a partir dos coeficientes de rendimento. Avaliação (Campinas), Sorocaba, SP, v. 21, n. 2, p. 569-591, jul. 2016

PEREIRA JUNIOR, Edgar. Compromisso com o graduar-se, com a instituição e com o curso: estrutura fatorial e relação com a evasão. 2012. 414p. Dissertação de Mestrado, Universidade Estadual de Campinas, 2012.

QUEIROZ, Z. C. L. S. et al. A lei de cotas na perspectiva do desempenho acadêmico na Universidade Federal de Uberlândia. Rev. bras. Estud. pedagog. (online), Brasília, v. 96, n. 243, p. 299-320, maio/ago. 2015. 


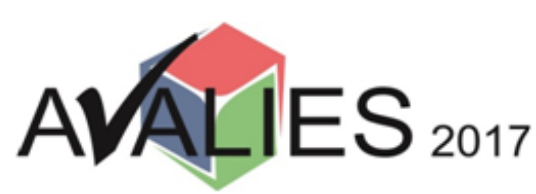

\section{$3^{\circ}$ Simpósio Avaliação da Educação Superior \\ 05 e 06 de setembro de 2017 \\ Florianópolis - SC - Brasil \\ ISBN: 978-85-68618-04-2}

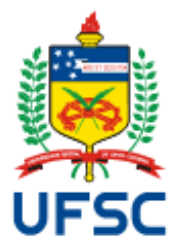

RAMOS, M. P.; SCHABBACH, L. M. O estado da arte da avaliação de políticas públicas: conceituação e exemplos de avaliação no Brasil. Rev. Adm. Pública, Rio de Janeiro, v. 46, n. 5, p. 1271-1294, Out. 2012.

RIOS, Rafaela, Análise do plano de permanência de estudantes da universidade federal do pampa. 2016. Dissertação de Mestrado, Universidade Federal de Santa Maria, Programa de Pósgraduação em Administração, 2016.

RISTOFF, D. Evasão: Exclusão ou Mobilidade. Santa Catarina, UFSC, 1995.

SILVA FILHO; LOBO; ROBERTO, L. H.; OSCAR, L.; MARIA, B. C. M.; MOTEJUNAS, P. R. A Evasão no Ensino Superior Brasileiro. Cadernos de Pesquisa, Fundação Carlos Chagas. set/dez. 2009- v.37, no 132. Disponível em: <http://goo.gl/k4ciUF>. Acesso em: 04 dez. 2016.

SOUSA, L. P.; PORTES, É. A. As propostas de políticas/ações afirmativas das universidades públicas e as políticas/ações de permanência nos ordenamentos legais. Estudos RBEP, Brasília, 92, n. 232, 2011. 516-541.

SOUZA, A. C.; BRANDALISE, M. A. T. Avaliação da política de cotas da UEPG: desvelando o direito à igualdade e à diferença. Avaliação (Campinas), Sorocaba, v. 21, n. 2, p. 415-438, Jul. 2016.

TRAGTENBERG, M. H. R. Programa de ações afirmativas da Universidade Federal de Santa Catarina: resultados preliminares. Revista GUAL, vol. 3(1), p. 144-159, 01. Dez. 2010.

TRESOLDI, T.; SIMÕES, L. J.; NABARRO, E.; POLIDORI, M. M. Análise de desempenho acadêmico de estudantes com ingresso por reserva de vagas na Universidade Federal do Rio Grande do Sul (UFRGS). In: SIMPÓSIO DE AVALIAÇÃO DA EDUCAÇÃO SUPERIOR, Porto Alegre, 2015. Anais... Porto Alegre, 2015.

UFSC. Plano de Desenvolvimento Institucional: 2004-2009. Florianópolis, SC, 2004. 610 p. Disponível em: <http://pdi.ufsc.br/files/2014/10/PDI-2004-2009.pdf〉. Acesso em: 06 dez. 2016.

Resolução no 017/CUn, de 30 de setembro de 1997. Dispõe sobre o Regulamento dos Cursos de Graduação da UFSC. Regulamento dos Cursos de Graduação. Florianópolis, SC. Disponível em:

<http://notes.ufsc.br/aplic/leis.nsf/0325638e006c665f8325632d006a99b5/d795a29a3834ad848325786 300500129/\$FILE/Res 17-CUn-1997.pdf>. Acesso em: 07 nov. 2016.

Resolução Normativa no 008/CUn, de 10 de julho de 2007. Cria o "Programa de Ações Afirmativas" da Universidade Federal de Santa Catarina. Programa de Ações Afirmativas. Florianópolis, SC, Disponível em: <http://acoesafirmativas.ufsc.br/files/2013/03/2716_R008CUN2007.pdf>. Acesso em: 07 nov. 2016.

VERGARA, S. C. Projetos e relatórios de pesquisa em administração. 12. ed. São Paulo: Atlas, 2010. 